\title{
APLICACÃO DA ANÁLISE MORFOMÉTRICA DE BACIAS HIDROGRÁFICAS COMO SUBSÍDIO AO ENTENDIMENTO DOS PROCESSOS CRESCENTES DE INUNDAÇÕES NA MALHA URBANA DA CIDADE DE UBÁ-MG
}

\author{
Jéssica Lana de Souza da Silva \\ Mestranda do Programa de Pós Graduação em Geografia \\ Universidade Federal de Juiz de Fora (UFJF), MG. Bolsista FAPEMIG. \\ jessicalanaufj@@gmail.com \\ Rômulo Montan Costa \\ Mestre em Geografia pelo Programa de Pós Graduação em Geografia \\ Universidade Federal de Juiz de Fora (UFJF), MG. \\ romulocosta.ufjf@hotmail.com \\ Ricardo Tavares Zaidan \\ Professor do departamento de Geociências e Programa de Pós-Graduação em Geografia \\ Universidade Federal de Juiz de Fora (UFJF), MG. \\ ricardo.zaidan@ufjf.edu.br
}

\begin{abstract}
RESUMO
As análises morfométricas são importantes ferramentas metodológicas na interpretação do comportamento hidrológico e da dinâmica geomorfológica de uma bacia hidrográfica. Tal assertiva ganha importância, a partir do momento em que os fenômenos de inundações compreendem um dos principais problemas ambientais na América Latina e Brasil. Nesse sentido, o objetivo do presente estudo é avaliar comparativamente, com base nas características lineares, zonais e hipsométricas, a morfometria de onze sub-bacias de contribuição do Ribeirão Ubá, a fim de apreender aspectos qualitativos que possibilitem subsidiar o entendimento de fatores intrínsecos às inundações da cidade de Ubá-MG. Para a realização das análises morfométricas gerou-se uma base cartográfica constituída por arquivos vetoriais e matriciais; os mesmos foram gerenciados, manejados e tratados através do software ArcGIS 10.1. Posteriormente, uma integração qualitativa dos resultados foi realizada indicando as sub-bacias do Ribeirão Ubá que apresentam características morfológicas mais propícias às inundações. Nesse sentido, três sub-bacias foram categorizadas como de alta suscetibilidade geomorfológica às inundações, devendo receber atenção especial. As mesmas foram denominadas como sub-bacias 5, 6 e 7, apresentando caracterítiscas de alta declividade, alta amplitude altimétrica e significativo número de canais de primeira ordem.
\end{abstract}

Palavras-chave: Alta suscetibilidade. Comportamento hidrológico. Integração Qualitativa. Sub-bacias.

\section{APPLICATION OF THE MORPHOMETRIC ANALYSIS OF HYDROGRAPHIC BASINS AS A SUBSIDY FOR UNDERSTANDING FLOOD DEVELOPMENT IN THE URBAN MESH OF THE CITY OF UBÁ-MG}

\begin{abstract}
Morphometric analyzes are important methodological tools in the interpretation of the hydrological behavior and geomorphological dynamics of a watershed. This assertion gains importance, from the moment that the flooding phenomena comprise one of the main environmental problems in Latin America and Brazil. In this sense, the objective of the present study is to evaluate comparatively, based on linear, zonal and hypsometric characteristics, the morphometry of eleven contribution sub-basins of Ribeirão Ubá, in order to apprehend qualitative aspects that allow the understanding of factors intrinsic to the floods in the city of Ubá-MG. To carry out the morphometric analysis, a cartographic base was created, consisting of vector and matrix files; they were managed, managed and treated using ArcGIS 10.1 Software. Subsequently, a qualitative integration of the results was performed, indicating the sub-basins of Ribeirão Ubá that present morphological characteristics more conducive to flooding. In this sense, three sub-basins were categorized as having high geomorphological susceptibility to flooding, and should receive special attention. They were named as subbasins 5,6 and 7, with characteristics of high declivity, high altimetric amplitude and significant number of first order channels
\end{abstract}

Keywords: High Susceptibility. Hydrological behavior. Qualitative integration. Sub-basins. 


\section{INTRODUÇÃO}

As bacias hidrográficas possuem, ligado a seus aspectos geomofológicos, susceptibilidade natural à ocorrência de enchentes e inundações. Assim, destaca-se que caracteristicas como morfologia das vertentes, padrão de drenagem, forma da bacia, declividade, tipologia dos canais fluviais, cobertura pedológica e vegetacional, encontram-se diretamente correlacionadas à velocidade de distribuição das águas pluviais pela superfície da unidade físico-territorial supramencionada (CHARLTON, 2008).

Ademais, de forma multiescalar, cabe ressaltar que as sub-bacias hidrográficas podem contribuir de modo diferenciado para maior concentração ou maior escoamento das águas de sua bacia principal. Nesse contexto, faz-se de fundamental importância conhecer os processos que encontram-se imbricados a sua caracterização morfométrica, concebida aqui como os aspectos geométricos da morfologia superficial (SUMMERFIELD, 1991). Toda essa conjuntura possibilita estudos de cunho mais aprofundado em questões que regem a dinâmica Ambiental e, por conseguinte, o comportamento hidrológico de uma bacia hidrográfica (LIMA, 2010).

Imerso nesse contexto, faz-se de fundamental importância distinguir e conceituar termos que são semelhantes e usualmente confundidos entre si. Rigorosamente falando, alagamento, enchente, enxurrada e inundação apresentam particularidades. As enchentes caracterizam-se pela elevação temporária do nível d'água em um canal de drenagem e por sua posterior redução, chamada de vazante, até retornar as vazões de base alimentadas pelo lençol subterrâneo (MIRANDA, 2016). No que se refere aos alagamentos, destaca-se que os mesmos concebem-se, de uma forma geral, como ocorrências pontuais em função de falhas no sistema de microdrenagem, podendo ter ou não relação com processos de natureza fluvial, contrapondo-se, assim, de forma marcante, aos eventos vinculados as enxurradas, haja vista que as mesmas caracterizam-se pelo escoamento superficial concentrado e pela alta energia de transportee em curto interval de tempo (IPT, 2007).

Dessa forma, ressalta-se que o meio ambiente natural agindo em concomitância com às grandes modificações socioeconômicas em espaços urbanos pode acarretar na intensifcação de efeitos que se interligam e contribuem para o estabelecimento do caos. No caso específico a ser trabalhado neste artigo, o conceito de inundação encontra-se relacionado a processos de escoamento pluvial, ou seja, caracteriza-se como um evento de caráter natural do ciclo hidrológico, mas que pode ser intensificado mediante $o$ aumento das taxas de impermeabilização do solo, principalmente no leito maior e menor do rio (Figura 1). Geralmente, o leito menor é aquele que possui o escoamento constante das águas (onde ocorem as enchentes), enquanto que o leito maior é inundado pelas águas com frequência comumente menor, porém com impactos e magnitudes maiores (TUCCI, 2003).

Figura 1- Ubá (MG): Características dos leitos dos rios, 2019.

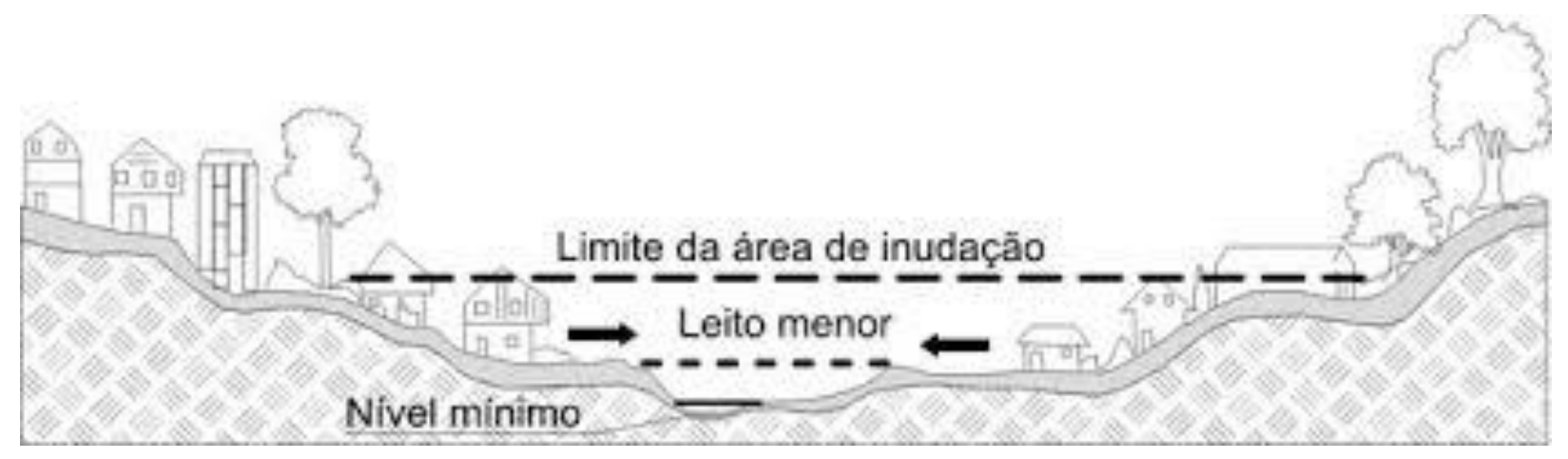

Fonte - Adaptado de TUCCI, 2003, p.25.

Quando os leitos maiores são ocupados e impermeabilizados por construções a probabilidade de aumento de risco à inundação é maior, situação notadamente perceptível nas cidades, onde o Plano Diretor Urbano não faz restrição a loteamentos nessas localidades. Tal fenômeno ocorre quando as 
águas dos rios ultrapassam o leito de escoamento e atingem as áreas de moradia, ruas, passeios, entre outros (TUCCI, 2003).

Dentro desse contexto, o desenvolvimento de estudos relacionados aos aspectos morfológicos da rede de drenagem facilita a compreensão da geomorfologia local, uma vez que os processos de morfogênese ativos são os principais responsáveis pela evolução da paisagem (CHRISTOFOLETTI, 1980). Um subsídio comumente utilizado para análise hidrológica se refere à caracterização morfométrica da área estudada, a qual propicia, a partir da combinação dos parâmetros morfométricos, pontuar diferenças em áreas homogêneas e identificar as possíveis fragilidades ambientais dentro de uma bacia (ANTONELI; THOMAZ, 2007).

Imerso nesse contexto, utilizou-se no presente artigo alguns parametros morfométricos, os quais contribuiram para o entendimento de fatores naturais atrelados ao desenvolvimento de inundações na malha urbana da cidade de Ubá-MG. Doravante, ressalta-se que o presente artigo visa identificar a configuração espacial do local, com cálculos geométricos, a partir de atributos do tipo: comprimento do canal principal, comprimento e área da bacia, declividade máxima e mínima dos canais, altimetria, número de canais, sinuosidade, entre outros. Para além da análise quantificada, faz-se necessário realizar uma interpretação qualitativa dos resultados na busca da compreensão dos aspectos geomorfológicos ocultos nos valores matemáticos.

Assim, o presente trabalho tem por objetivo avaliar a suscetibilidade geomorfológica à inundações na cidade de Ubá-MG a partir de análises morfométricas com base nas características lineares, zonais e hipsométricas de onze sub-bacias ${ }^{1}$ de contribuição do rio principal, a partir da utilização das Geotecnologias. Pretende-se, a partir desse estudo, espacializar as informações obtidas e gerar produtos cartográficos que auxiliem na compreensão dos processos decorrentes da dinâmica geomorfológica e hidrológica das sub-bacias em estudo, a fim de apreender aspectos qualitativos que possibilitem subsidiar o entendimento de fatores intrínsecos à inundação, permitindo assim elucidar as que possuem maior potencial de contribuição no que tange a ocorrência de eventos ligados aos processos de inundação na malha urbana de Ubá-MG.

\section{ÁREA DE ESTUDO}

Com uma área de 125,90 Km², a bacia hidrográfica do Ribeirão Ubá, selecionada para a realização do presente trabalho, integrante da bacia do Rio Paraíba do Sul, encontra-se localizada na mesorregião da Zona da Mata do estado de Minas Gerais, entre as coordenadas $21^{\circ} 00^{\prime}$ e $21^{\circ} 10^{\prime}$ de latitude sul e $42^{\circ} 53^{\prime}$ e $43^{\circ} 3^{\prime}$ de longitude oeste (Figura 2). Sua área encontra-se inserida quase que em sua totalidade no município de Ubá, mais precisamente no distrito de Miragaia, em parte do distrito sede de Ubá e, uma pequena porção, a sudoeste do município de Divinésia, totalizando, respectivamente, áreas de: $43,7 \mathrm{~km}^{2}, 68,25 \mathrm{~km}^{2}$ e $13,95 \mathrm{~km}^{2}$. O rio principal atravessa a cidade de noroeste a sudoeste da malha urbana, percorrendo uma distância de aproximadamente $24 \mathrm{~km}$, onde está localizado o exutório da bacia em questão.

A expansão urbana de Ubá ocorreu, apesar das condições desfavoráveis impostas pelo relevo, ao longo das terras baixas nas margens do ribeirão homônimo. Todavia, observa-se que diferentemente do que é visto em diversos casos, a planície de inundação da cidade, considerada área de risco, tem, de uma forma geral, como base de ocupação a presença de pessoas de classe média, sendo estes os que mais sofrem, em termos econômicos, os prejuízos acarretados pelas inundações.

\footnotetext{
${ }^{1}$ Neste trabalho a terminologia "sub-bacia" é utilizada para a identificação de bacias hidrográficas hierarquicamente inferiores a uma bacia principal, como fragmentos inseridos na área de estudo. Neste sentido, a terminologia adotada facilita a compreensão da ideia de subordinação da rede de drenagem, independentemente da sua área de abrangência. 
Figura 2 - Ubá (MG): Mapa de localização do Município de Ubá e Bacia Hidrográfica do Ribeirão Ubá,

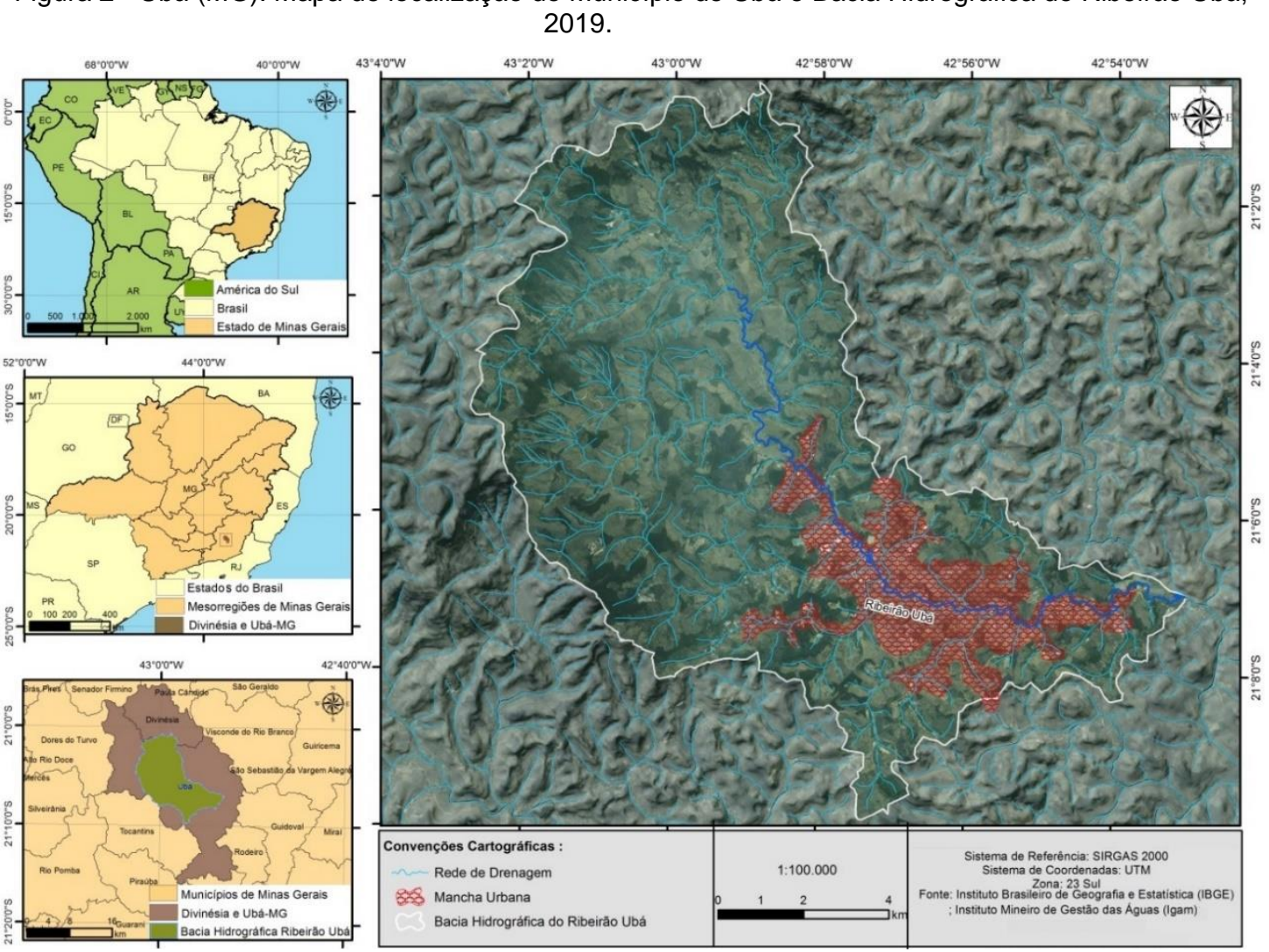

Fonte - Elaborado pelos autores.

Segundo observou Valverde (1958), esta parte do Estado não se diferenciava das demais regiões vizinhas pelas características de sua vegetação, mas, sobretudo, pelas características marcantes do relevo definidas por alinhamentos de cristas e por superfícies deprimidas no interior da região. Nesse contexto a área do presente estudo encontra-se localizada sob o domínio da unidade geomorfológica dos planaltos cristalinos rebaixados, também denominados de Domínio Morfoclimático de Mar de Morros, definida por (Ab' Sáber, 2003, p.55) como: "área de mais profunda decomposição das rochas e de máxima presença de mamelonização topográfica em caráter regional de todo país", ou seja, características essas que imprimem a esta região dinâmica superficial intensa. As combinações destes fatores com elevados índices pluviométricos desencadeiam nessa região intensos processos de intemperismo químico, de erosão hídrica e de movimentos de massa, além de enchentes e inundações, foco do presente estudo. Tais características, associadas ao parco planejamento urbano-territorial, acarretam, invariavelmente, em prejuízos de ordem econômica, social e em perdas de vidas humanas.

No que se refere ao clima, o estudo realizado por Andrade (1961) elucidou a presença de uma temperatura média anual de $23^{\circ} \mathrm{C}$, atingindo nos meses de verão temperaturas superiores a $26^{\circ} \mathrm{C}$, período este responsável por grandes precipitações e, consequentemente, pelo aumento dos fenômenos referentes às inundações. Ainda segundo o autor supracitado, o município de Ubá apresenta período de chuvas característico, com uma estação chovosa bem definida, a qual estendede outubro a abril, atingindo uma taxa pluviométrica anual de $1500 \mathrm{~mm}$, com destaque para o mês de fevereiro $(271,8 \mathrm{~mm})$.

Concebido como o centro econômico microrregional, o municipio de Ubá caracteriza-se por sua posição privilegiada, distando $290 \mathrm{~km}$ da capital do Estado- Belo Horizonte, $300 \mathrm{~km}$ da cidade do Rio de Janeiro, 580 km da cidade de São Paulo, 1.004 km de Brasília e 470 km da cidade de Vitória (UBÁ,2011). Tais fatores imprimiram ao município um acelerado crescimento econômico, sobretudo, no que se refere ao 
setor industrial vinculado ao setor moveleiro, concebendo-se o maior polo de Minas Gerais e o terceiro no Brasil em números de empresa (SOUZA, 2008).

Os processos de expansão industrial e de modernização dos serviços alteraram a realidade socioeconômica do município de Ubá, desencadeando a partir da década de 1970, com a instalação dos setores industriais e, posteriormente, com capacitação destes na década de 1990, em um deslocamento populacional das áreas rurais para as áreas urbanas, resultando assim no processo de urbanização.

A partir da década de noventa, o crescimento populacional de Ubá torna-se acelerado, sendo a taxa anual de $2,31 \%$, percentual este superior à média brasileira que é de $1,8 \%$. O processo de urbanização cresceu consideravelmente, chegando ao ano de $2010 \mathrm{com}$ uma população concentrada na área urbana de aproximadamente $95 \%$ e apenas 5\% na área rural (UBÁ, 2011, p.23).

Entre 2000 e 2010 a população de Ubá cresceu de forma significativa, apresentando taxas de crescimento demográfico de até $1,78 \%$ anual. Nesta década, a taxa de urbanização do município passou de 90,15\% para 96,18\%, segundo dados do censo do Institutito Brasileiro de Geografia e Estatística (IBGE, 2010). No ano de 2020 a população estimada foi de 116.797 habitantes (IBGE, 2020).

\section{METODOLOGIA}

A metodologia do trabalho perpassa a coleta e tratamento de dados espaciais. Em síntese, foram aplicados parâmetros morfométricos diversos relacionados à suscetibilidade geomorfológica às inundações nas sub-bacias de contribuição do Ribeirão Ubá. Posteriormente, os dados foram interpretados por estatística qualitativa de agrupamento para fins de comparação, conforme apresentado por Souza (2005). Assim, o trabalho aqui disposto pode ser dividido em quatro etapas: levantamento bibliográfico e cartográfico; processamento digital dos dados obtidos; análises morfométricas; análise qualitativa.

O software utilizado neste trabalho foi o ArcGis, versão 10.1 (ESRI,2014) manuseado no georreferenciamento, gestão, análise espacial, edição e manipulação dos dados geográficos. As bases cartográficas utilizadas foram cedidas pelo Instituto Mineiro de Gestão das Águas (IGAM) e IBGE, na escala de 1:50.000. Estas foram estruturadas através do sistema de referência Sirgas 2000, sistemas de coordenadas Universal Transversa de Mercator (UTM) e fuso 23 sul.

Inicialmente, foi realizada uma revisão da literatura baseada, sobretudo, em pesquisas que abordavam técnicas voltadas aos estudos morfométricos, voltados ao potencial de contribuição de bacias de drenagem ao desenvolvimento de inundações, tendo como principais fontes autores como: Cherem (2008); Christofoletti (1980; 1981); Souza (2005); Tucci (2000; 2003); entre outros.

O mapeamento da área de estudo desenvolveu-se no software ArcGis, englobando o georreferenciamento das cartas topográficas por meio da ferramenta georreferenciamento e delimitação das sub-bacias hidrográficas do Ribeirão Ubá e da malha Urbana do município de Ubá-MG através da ferramenta "edição de polígonos", visto que uma classificação automática ou semiautomática poderia refletir na união ou exagero no número de sub-bacias delimitadas. Tal procedimento foi executado sob as cartas topográficas de Ubá-MG (SF-23-X-D-II-1) e Tocantins (SF23-X-D-I-2), na escala de 1:50.000 (IBGE), possibilitando a seleção dos rios e córregos contribuintes do rio principal que cortam a malha urbana do município. Levou-se em consideração o final do perímetro urbano como exutório da bacia em análise, isso porque o objetivo é de aplicar os parâmetros morfométricos em cada uma das sub-bacias que contribuam para a drenagem da área urbana. $O$ critério de seleção dessas áreas foi o de se trabalhar com sub-bacias de terceira e quarta ordem, desde que deságuassem no rio principal (Figura 3).

Figura 3 - Ubá (MG): Sub-bacias hidrográficas do Ribeirão Ubá, 2019. 

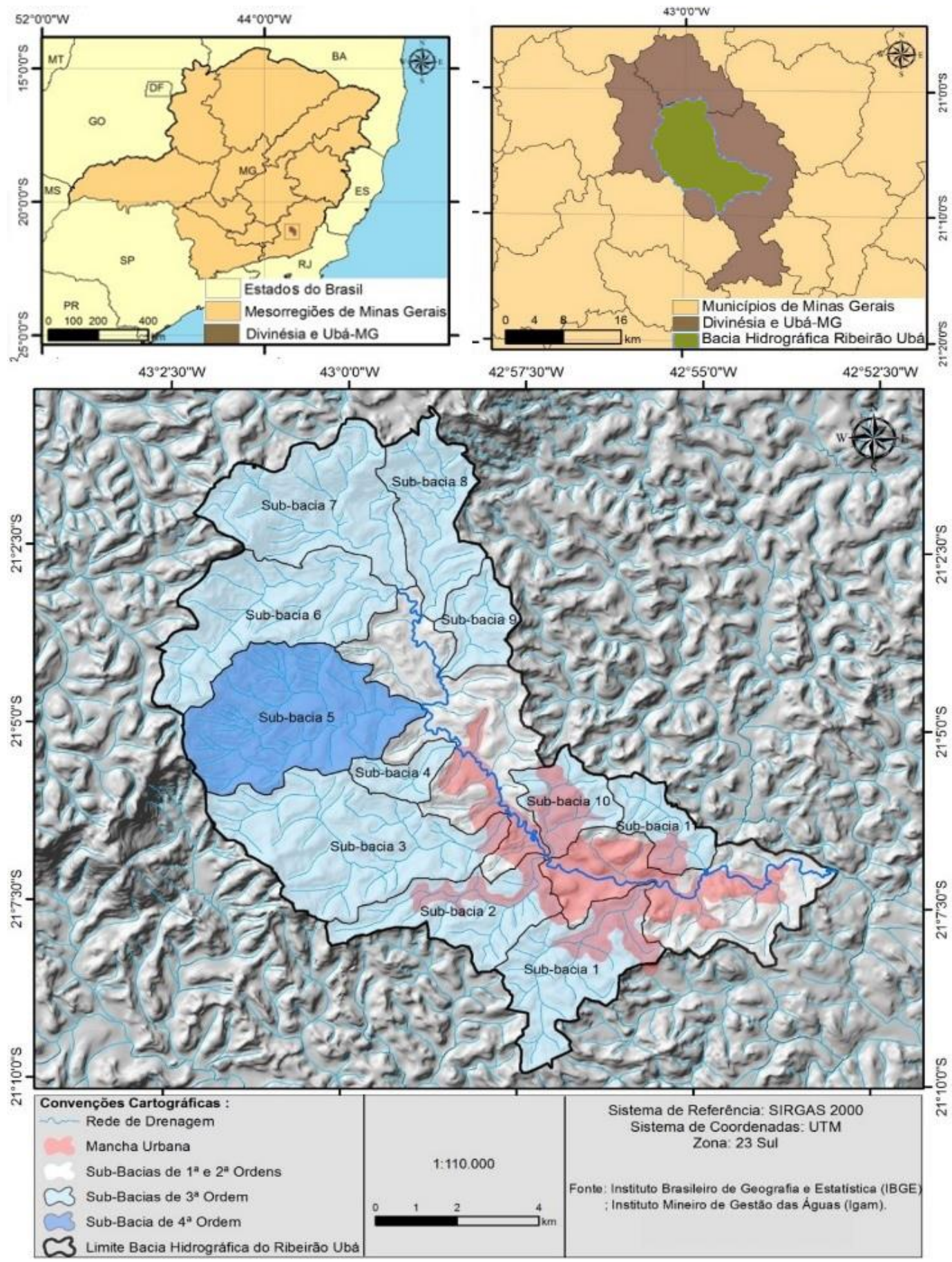

Fonte - Elaborado pelos autores.

A escolha dos parâmetros morfométricos utilizados neste artigo partiu de uma revisão bibliográfica sobre a temática. Para tal, foram selecionados os que apresentavam maior relação com o potencial de contribuição para o desenvolvimento de inundações, sendo estes: área, perímetro, comprimento do canal principal e de toda a rede de drenagem da bacia, amplitude altimétrica, ordem do córrego, densidade de drenagem, índice de circularidade, forma da bacia, frequência de canais de $1^{\text {a }}$ ordem, fator forma, declividade do canal principal e da bacia.

A descrição dos parâmetros selecionados, bem como a justificativa para sua escolha dos mesmos, encotra-se apresentado na Quadro 1:

Quadro 1 - Ubá (MG): Parâmetros morfométricos e suas devidas descrições, 2019.

Caminhos de Geografia Uberlândia-MG $\quad$ v. 22, n. $82 \quad$ ago./2021 $\quad$ p. 201-214 Página 206




\begin{tabular}{|c|c|}
\hline $\begin{array}{c}\text { Parâmetros } \\
\text { Morfométricos }\end{array}$ & Descrição \\
\hline $\begin{array}{l}\text { Ordem Hierárquica } \\
\text { dos Canais(0) }\end{array}$ & $\begin{array}{l}\text { Para Strahler, os menores canais, sem tributários, são considerados como de primeira } \\
\text { ordem, estendendo-se desde a nascente até a confluência; os canais de segunda } \\
\text { ordem surgem da confluência de dois canais de primeira ordem, e só recebem } \\
\text { afluentes de primeira ordem; os canais de terceira ordem surgem de confluência de } \\
\text { dois canais de segunda ordem, podendo receber afluentes de segunda e de primeiras } \\
\text { ordens; os canais de quarta ordem surgem da confluência de dois canais de terceira } \\
\text { ordem, podendo receber tributários das ordens inferiores. E assim sucessivamente. } \\
\text { (CRISTOFOLETTI, 1980) }\end{array}$ \\
\hline $\begin{array}{l}\text { Área da Bacia de } \\
\text { Drenagem (A) }\end{array}$ & $\begin{array}{l}\text { É toda a área drenada pelo conjunto do sistema fluvial, projetada em plano horizontal. } \\
\text { Determinado o perímetro da bacia, a área pode ser calculada com auxílio do } \\
\text { planímetro, de papel milimetrado, pela pesagem de papel uniforme devidamente } \\
\text { recortado ou através de técnicas mais sofisticadas, com uso do computador. } \\
\text { (CRISTOFOLETTI, 1980). }\end{array}$ \\
\hline $\begin{array}{l}\text { Perímetro da Bacia } \\
\text { de Drenagem }(\mathrm{P})\end{array}$ & $\begin{array}{l}\text { Corresponde à projeção horizontal da linha que contorna o divisor de águas da bacia } \\
\text { (Zãvoianu, } 1985 \text { apud SOUZA, 2005) }\end{array}$ \\
\hline $\begin{array}{l}\text { Frequência de } \\
\text { Canais de Primeira } \\
\text { Ordem } \\
\left(\mathbf{C} \% 1^{a}\right)\end{array}$ & $\begin{array}{l}\text { É a frequência percentual de canais de primeira ordem em relação ao número total de } \\
\text { canais. Blyty \& Rodda (1973 apud Patton \& Baker, 1976) notaram que o número de } \\
\text { canais de } 1^{\text {a }} \text { ordem pode aumentar em até } 20 \% \text { durante chuvas intensas sendo, } \\
\text { portanto, dependente do volume total e da intensidade das chuvas. Segundo Morisawa } \\
\text { (1962), um elevado número de canais de } 1^{\underline{a}} \text { ordem conduz a um rápido fluxo de água } \\
\text { para fora da bacia, bem como mais chuva sendo conduzida para fora das cabeceiras, } \\
\text { muito mais do que pela infiltração ou pelo solo (SOUZA, 2005). }\end{array}$ \\
\hline $\begin{array}{l}\text { Comprimento Total } \\
\text { do Canal Principal } \\
\text { (L) }\end{array}$ & $\begin{array}{l}\text { É a distância que se estende ao longo do curso de água desde a desembocadura até } \\
\text { determinada nascente. O critério utilizado para realização deste trabalho foi o de } \\
\text { Shereve (1974: 1168), onde o curso de água mais longo é aquele que medindo da } \\
\text { desembocadura da bacia até determinada nascente apresenta valor maior. } \\
\text { (CRISTOFOLETTI, 1980) }\end{array}$ \\
\hline Forma da Bacia (Fg) & $\begin{array}{l}\text { Representa a figura geométrica que melhor se ajusta à área da bacia, podendo ser: } \\
\text { circular, quadrangular ou quadrada, triangular e retangular (Lee \& Salle, 1970). É } \\
\text { independente da escala (SOUZA, 2005). }\end{array}$ \\
\hline $\begin{array}{l}\text { Índice de } \\
\text { Circularidade (Ic) }\end{array}$ & $\begin{array}{l}\text { Relação existente entre a área da bacia e a área do círculo do mesmo perímetro. } \mathrm{O} \\
\text { máximo valor a ser obtido é igual a } 1,0 \text {, e quanto maior o valor, mais próxima da forma } \\
\text { circular estará a bacia de drenagem. Obtido a partir da fórmula: } \mathrm{C}=\mathrm{A} / \mathrm{Ac} \text {, onde } \mathrm{A} \\
\text { representa a área da bacia, Ac e a área do círculo de perímetro igual ao da bacia } \\
(\text { CRISTOFOLETTI, 1980). }\end{array}$ \\
\hline Fator Forma (Kf) & $\begin{array}{l}\text { É obtido pela razão entre a área da bacia }(A) \text { e o quadrado do comprimento (L) do seu } \\
\left.\text { canal principal: } K f=A / L^{2} \text { (Chorley } E T A L ., 1957\right) \text {. Uma bacia de forma baixo (estreita e } \\
\text { longa) é menos suscetível à inundação/enchentes do que outra de mesmo tamanho, } \\
\text { porém com maior fator de forma (circular, por exemplo) (SOUZA, 2005) }\end{array}$ \\
\hline $\begin{array}{l}\text { Densidade de } \\
\text { Drenagem (Dd) }\end{array}$ & 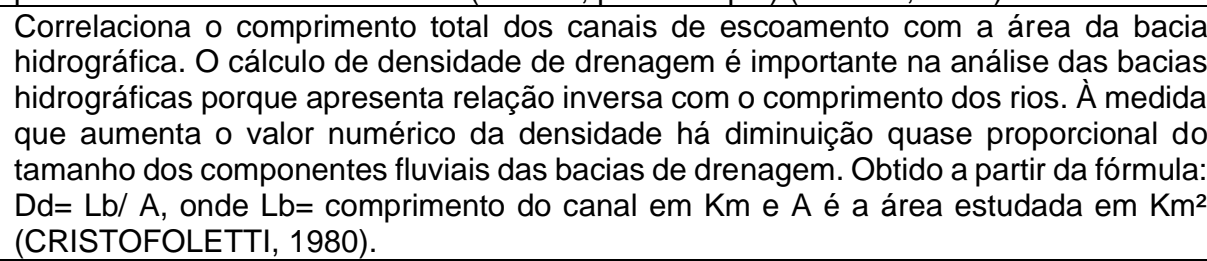 \\
\hline $\begin{array}{l}\text { Índice de } \\
\text { Sinuosidade (IS) }\end{array}$ & $\begin{array}{l}\text { Como explicado por Granell- Pérez (2001, p.84), nas cartas topográficas de 1:50.000, } \\
\text { também podem ser identificados os canais fluviais que descrevem sinuosidades ou } \\
\text { voltas acentuadas e redondeadas denominados meandros, cuja formação resulta da } \\
\text { combinação das ações erosivas e deposicionais dos rios na busca de equilíbrio. Obtido } \\
\text { a partir da fórmula: IS= (L/ Dv), onde L é o comprimento do canal principal e Dv é a } \\
\text { distancia vetorial entre os pontos extremos do canal principal (MACHADO, 2012). }\end{array}$ \\
\hline $\begin{array}{l}\text { Declividade Média } \\
\text { do Canal Principal } \\
\text { (Smc) e da bacia } \\
\text { (Smb) }\end{array}$ & $\begin{array}{l}\text { Corresponde à tangente do ângulo (á) de inclinação da superfície do terreno ao longo } \\
\text { do canal principal da bacia, medido a partir do segmento em linha reta de comprimento } \\
\mathrm{L} \text { do canal que se estende entre os pontos mais baixo, e mais alto da bacia, sendo } \\
\text { definida pela expressão: tan à? H/L. A declividade é relacionada diretamente com o } \\
\text { tipo e a resistência de rochas à erosão e ao intemperismo. Tem um papel fundamental } \\
\text { nos processos fluviais, na formação do escoamento superficial, no movimento das } \\
\text { inundações/enchentes, no poder potencial dos fluxos fluviais, nos processos de } \\
\text { erosão, transporte e deposição na modelagem evolução da rede de drenagem } \\
\text { (Zãvoianu, 1985). Canais com altas declividades são menores, têm maior energia } \\
\text { hidráulica (maior capacidade de erosão e transporte) e carregam menos água (menor } \\
\text { descarga) do que canais com baixa declividade, os quais são mais longos mais }\end{array}$ \\
\hline
\end{tabular}




\begin{tabular}{|c|l|}
\hline & $\begin{array}{l}\text { profundos e possuem maior estoque de água (maior descarga) e menor energia } \\
\text { (Morisawa, 1962). O parâmetro é obtido através da expressão: tan à= ¿H/L, onde á } \\
\text { corresponde a tangente do ângulo de inclinação da superfície do terreno ao longo do } \\
\text { canal principal da bacia, medido a partir do segmento em linha reta do comprimento } \\
\text { (L) do canal que se estende entre os pontos mais baixos (H1) e mais altos (H2) da } \\
\text { bacia (SOUZA, 2005). }\end{array}$ \\
\hline $\begin{array}{c}\text { Amplitude } \\
\text { altimétrica (Apat) }\end{array}$ & Relação entre a diferença máxima e mínima de altitude. \\
\hline $\begin{array}{c}\text { Índice de } \\
\text { Rugosidade (Ir) }\end{array}$ & $\begin{array}{l}\text { O parâmetro Índice de Rugosidade (Ir), segundo Strahler (1958) representa uma inter- } \\
\text { relação entre a declividade e o comprimento da vertente através do contrabalanço da } \\
\text { amplitude altimétrica e à densidade de drenagem. Obtido a partir da expressão: Ir= } \\
\text { HxDd, onde H representa a amplitude altimétrica e Dd representa a densidade de } \\
\text { drenagem (SOUZA, 2005). }\end{array}$ \\
\hline
\end{tabular}

Fonte - Organizado pelos autores.

Destarte, realizou-se a extração dos dados geométricos, do comprimento do rio principal, área e perímetro da bacia, dentre outros, de cada arquivo vetorial presente no trabalho. Esse procedimento baseou-se na adição de um novo campo à tabela de atributos para seu posterior cálculo, o qual foi realizado através dos seguintes passos: Tabela de Atributos > Opções de Tabela > Adicionar Campo $>$ Duplo > Calcular Geometria. Após extração e cálculo dos dados geométricos, os mesmos foram transferidos para o programa Microsoft Excel, utilizado para correlação dos dados geométricos em uma planilha eletrônica, auxiliando na execução dos cálculos matemáticos referentes aos parâmetros morfométricos de cada sub-bacia presente na área de estudo.

O passo seguinte baseou-se na análise e classificação de cada parâmetro trabalhado, levando-se em conta as especificidades dos valores obtidos no que se refere a sua correlação com cada sub-bacia, haja vista a relação de dependência entre ambos. Esse procedimento foi realizado no software ArcGis. Os valores referentes a cada parâmetro morfométrico foram adicionados a tabela de atributos, estes foram estruturados e classificados em três classes. O método utilizado para a realização da classificação pautou-se na Quebra Natural (Natural Break). O método da Quebra Natural, de Jenks (1967), busca particionar os dados inseridos em intervalos naturais, agrupando os dados que possuem as menores variações e distribuindo-os de forma homogênea, minimizando assim a varância dentro das classes.

Após a etapa de identificação de cada intervalo referente aos parâmetros morfométricos em estudo, partiu-se para o proxímo passo, o qual baseou-se na atribuição de notas referentes a cada sub-bacia. Para a atribuiçào das notas, levou-se em conta as particularidades dos parâmetros morfométricos analisados, visto que, estes possuem relações direta e inversamente proporcionais entre $\mathrm{si}^{2}$. A atribuição das notas considerou o grau de contribuição de cada sub-bacia para a ocorrência de inundações na malha urbana da cidade de Ubá, sendo classificadas da seguinte maneira: Alto $=3$ pontos; Médio $=2$ pontos; Baixo $=1$ ponto.

O quarto e último procedimento baseou-se no somatório das notas individuais referentes a cada subbacia, os valores obtidos foram transferidos para o software ArcGis e classificados em três intervalos de acordo com o método da quebra natural de Jenks (1967). Procedimento este que ao final atribui três classes as sub-bacias presentes na área de estudo, classificando-as quanto ao seu grau de

${ }^{2}$ Conforme apresentado e recomendado por Souza (2005). 
contribuição para à ocorrência de inundações da malha urbana da cidade de Ubá-MG em: Alto, Médio e Baixo.

\section{RESULTADOS E DISCUSSÕES}

$\mathrm{Na}$ tabela 1 apresenta-se os resultados obtidos referentes às analises areais, lineares, hipsométricas e qualitativas aplicadas e os respectivos potenciais de contribuição de cada sub-bacia hidrográfica ao desenvolvimento de inundaçõe na malha urbana da cidade de Ubá.

Tabela 1 - Ubá (MG): Parâmetro morfométricos aplicados na área de estudo, 2019.

\begin{tabular}{|c|c|c|c|c|c|c|c|c|c|c|c|c|c|}
\hline Rótulos & Área & Perímetro & $\mathbf{L}$ & 0 & Dd & Ic & Is & ApatB & SmC & SmB & $\mathrm{Cn}^{\mathrm{a}} \mathrm{O}$ & Ir & $\mathbf{K f}$ \\
\hline $\begin{array}{l}\text { Sub-bacia } \\
1\end{array}$ & 9,42 & 18,44 & 6,68 & 3 & 1,99 & 0,027 & 1,21 & 150 & 11,8 & 25 & 78,94 & 74,62 & 0,21 \\
\hline $\begin{array}{l}\text { Sub-bacia } \\
2\end{array}$ & 7,86 & 17,43 & 6,93 & 3 & 2,27 & 0,025 & 0,91 & 200 & 19,4 & 23 & 78,94 & 92,59 & 0,16 \\
\hline $\begin{array}{l}\text { Sub-bacia } \\
3\end{array}$ & 16,39 & 21,4 & 9,73 & 3 & 2,17 & 0,035 & 1,39 & 380 & 19,43 & 26 & 80,55 & 194,9 & 0,17 \\
\hline $\begin{array}{l}\text { Sub-bacia } \\
4\end{array}$ & 2,28 & 7,62 & 2,84 & 3 & 1,87 & 0,039 & 1,25 & 260 & 50 & 22 & 57,14 & 298,9 & 0,28 \\
\hline $\begin{array}{l}\text { Sub-bacia } \\
5\end{array}$ & 15,42 & 18,64 & 7,04 & 4 & 2,74 & 0,044 & 1,24 & 480 & 44,9 & 32 & 77,77 & 190,5 & 0,31 \\
\hline $\begin{array}{l}\text { Sub-bacia } \\
6\end{array}$ & 13,08 & 20,33 & 9,88 & 3 & 2,18 & 0,031 & 1,6 & 460 & 47,22 & 30 & 84,61 & 215 & 0,13 \\
\hline $\begin{array}{l}\text { Sub-bacia } \\
7\end{array}$ & 12,56 & 18,86 & 8,27 & 3 & 2,1 & 0,035 & 2,11 & 540 & 63,2 & 32 & 80,76 & 252,3 & 0,18 \\
\hline $\begin{array}{l}\text { Sub-bacia } \\
8\end{array}$ & 7,65 & 15,74 & 6,41 & 3 & 2,28 & 0,03 & 1,24 & 480 & 67,7 & 28 & 78,57 & 229,7 & 0,17 \\
\hline $\begin{array}{l}\text { Sub-bacia } \\
9\end{array}$ & 3,76 & 9,78 & 3,39 & 3 & 1,81 & 0,039 & 1,13 & 160 & 35,5 & 22 & 66,66 & 100,6 & 0,32 \\
\hline $\begin{array}{l}\text { Sub-bacia } \\
10\end{array}$ & 4,18 & 10,33 & 3,3 & 3 & 2,14 & 0,039 & 1,39 & 110 & 35,4 & 25 & 70 & 46,02 & 0,38 \\
\hline \multirow[t]{2}{*}{$\begin{array}{l}\text { Sub-bacia } \\
11\end{array}$} & 3,78 & 9,85 & 3,57 & 3 & 2,21 & 0,038 & 1,15 & 150 & 17,1 & 25 & 76,92 & 81,08 & 0,29 \\
\hline & $\mathrm{Km}^{2}$ & $\mathrm{~km}$ & $\mathrm{~km}$ & & $\mathrm{~km}^{2} / \mathrm{km}$ & & & $\mathrm{m}$ & $\%$ & $\%$ & $\%$ & & \\
\hline Rótulos & Área & $\mathbf{L}$ & 0 & Dd & Ic & Is & ApatB & SmC & SmB & Cn1 ${ }^{\mathrm{a}} \mathrm{O}$ & Ir & $\mathrm{Kf}$ & SOMA \\
\hline $\begin{array}{l}\text { Sub-bacia } \\
1\end{array}$ & 2 & 2 & 2 & 1 & 1 & 1 & 1 & 1 & 2 & 2 & 1 & 1 & 17 \\
\hline $\begin{array}{l}\text { Sub-bacia } \\
2\end{array}$ & 2 & 2 & 2 & 2 & 1 & 1 & 1 & 1 & 1 & 2 & 1 & 1 & 17 \\
\hline $\begin{array}{l}\text { Sub-bacia } \\
3\end{array}$ & 3 & 3 & 2 & 2 & 2 & 2 & 2 & 1 & 2 & 3 & 2 & 1 & 25 \\
\hline $\begin{array}{l}\text { Sub-bacia } \\
4\end{array}$ & 1 & 1 & 2 & 1 & 3 & 2 & 2 & 3 & 1 & 1 & 3 & 3 & 23 \\
\hline $\begin{array}{l}\text { Sub-bacia } \\
5\end{array}$ & 3 & 2 & 3 & 3 & 3 & 2 & 3 & 2 & 3 & 2 & 2 & 3 & 31 \\
\hline $\begin{array}{l}\text { Sub-bacia } \\
6\end{array}$ & 3 & 3 & 2 & 2 & 2 & 2 & 3 & 2 & 3 & 3 & 2 & 1 & 28 \\
\hline $\begin{array}{l}\text { Sub-bacia } \\
7\end{array}$ & 3 & 3 & 2 & 2 & 2 & 3 & 3 & 3 & 3 & 3 & 3 & 2 & 32 \\
\hline $\begin{array}{l}\text { Sub-bacia } \\
8\end{array}$ & 2 & 2 & 2 & 2 & 2 & 2 & 3 & 3 & 2 & 2 & 2 & 2 & 26 \\
\hline $\begin{array}{l}\text { Sub-bacia } \\
9\end{array}$ & 1 & 1 & 2 & 1 & 3 & 1 & 1 & 2 & 1 & 1 & 1 & 3 & 18 \\
\hline $\begin{array}{l}\text { Sub-bacia } \\
10\end{array}$ & 1 & 1 & 2 & 2 & 3 & 2 & 1 & 1 & 2 & 1 & 1 & 3 & 20 \\
\hline $\begin{array}{l}\text { Sub-bacia } \\
11\end{array}$ & 1 & 1 & 2 & 2 & 3 & 1 & 1 & 1 & 2 & 2 & 1 & 3 & 20 \\
\hline
\end{tabular}

Comprimento do canal principal (L), Ordem hierárquica (O) Segundo Strahler (1952), Densidade de drenagem (Dd), Índice de circularidade (Ic), Índice de sinuosidade (Is), Amplitude altimétrica da bacia (ApatB), Declividade médida da bacia $(\mathrm{SmB})$, Frequência de canais de primeira ordem $\left(\mathrm{Cn} 1^{\mathrm{a}} \mathrm{O}\right)$, Índice de rugosidade (Ir), Fator forma (Kf). Fonte: Organizado pelos autores (2019). 
As bacias que apresentam alto potencial de contribuição para o desenvolvimento de inundação na malha urbana da cidade de Ubá-MG são as denominadas sub-bacia 5, sub-bacia 6 e sub-bacia 7 (identificadas na tabela na cor azul escuro). É importante ressaltar que três das quatro maiores subbacias em termos de área e perímetro encontram-se inseridas nesse grupo. Estas apresentam como característica os seguintes fatores: a ordem hierárquica varia de 3 a 4 (duas sub-bacias de ordem 3; e uma sub-bacia de ordem 4 , sendo está a única sub-bacia classificada nesta ordem no presente trabalho); o fator forma varia de 0,13 a 0,31; o comprimento do canal principal varia de 7,04 km a 9,88 $\mathrm{km}$ (coincidindo com três das maiores sub-bacias da área de estudo); os perímetros variam entre 18,64 e $20,33 \mathrm{~km}$; a frequência de canais de 1 a ordem é maior do que $77,77 \%$ e menor do que $84,61 \%$ (subbacia 6), sendo que em 6 das 11 sub-bacias predominam valores acima de 77,77\%; a amplitude altimétrica de ambas sub-bacias variam de 460 a 540 metros. O parâmetro da amplitude altimétrica é responsável pela maior diferença no que se refere aos valores obtidos na aquisição dos dados morfométricos, contexto este mantido nos valores referentes as declividades médias dos canais principais e de cada sub-bacia, com valores variando respectivamente de 44,9 a $63,2 \%$ e 30 a $32 \%$; o índice de circularidade oscilou entre 0,031 a 0,044. Faz-se importante ressaltar que a declividade media da bacia apresentou variabilidade pequena entre as onze sub-bacias; o índice de sinuosidade variou de 1,24 m a 2,11m (sub-bacia 7), sendo este o maior valor dentre as onze sub-bacias; índice de rugosidade esteve entre 190,47 e 252,33 .

As sub-bacias com médio potencial de contribuição ao processo de inundação são: sub-bacia (3), subbacia (4) e sub-bacia (8). Cabe ressaltar que dentre as onze sub-bacias analizadas, identificou-se nas sub-bacias 3 e 4, respectivamente, o maior e menor valor se tratando da área, perímetro e comprimento do rio principal. IVereficou-se as seguintes características nesse agrupamento: as três sub-bacias são de $3^{a}$ ordem; o fator forma varia de 0,17 a 0,28; o comprimento dos canais principais varia de $2,84 \mathrm{~km}$ a 9,73 km; a área total das bacias varia entre $2,28 \mathrm{~km}^{2}$ e 16,39 $\mathrm{km}^{2}$, o perímetro varia entre $7,62 \mathrm{~km}$ e $21,4 \mathrm{~km}$; a frequência de canais de 1 a ordem varia de $57,14 \%$ a $80,55 \%$; a declividade dos canais principais vai de $14,38 \%$ até $62,40 \%$ (sendo este o maior valor dentre as onze sub-bacias); a amplitude altimétrica varia de $260 \mathrm{~m}$ a $480 \mathrm{~m}$; a densidade de drenagem varia de $1,87 \mathrm{~km}^{2}$ a 2,28 km².

O último grupo, caracterizado pelas sub-bacias com baixo potencial de contribuição ao processo de inundação se faz representado pelas seguintes sub-bacias: sub-bacia 1, sub-bacia 2, sub-bacia 9 , subbacia 10 e sub-bacia 11. Estas, apresentam as seguintes características: todas são de $3^{\text {a }}$ ordem hierárquica, a área varia de $3,76 \mathrm{~km}^{2}$ a 9,42 km²; perímetro entre $9,78 \mathrm{~km}$ e $18,44 \mathrm{~km}$; o comprimento dos canais principais são pequenos, variando de 3,3 Km a 6,93 Km; a densidade de drenagem está

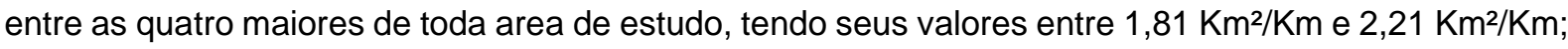
o índice de sinuosidade variou de 0,91 m a 1,39 m; a declividade média do canal variou de 8,98 \% a 35,39\%. A amplitude altimétrica varia de $110 \mathrm{~m}$ a $200 \mathrm{~m}$, representando as áreas de menores diferenças altimétricas. A declividade média da bacia varia de $22 \%$ a $25 \%$; a frequência dos canais de primeira ordem varia de $66,66 \%$ a 78,94 \%; os índices de rugosidade apresentam os menores valores, variando de 46,02 a 100,62; o coeficiente de forma variou de 0,16 a 0,38, sendo este último o maior valor obtido dentre onze sub-bacias.

A Figura 5 trás o mapa das sub-bacias com seus respectivos potenciais de contribuição a inundação de acordo com sua classificação morfométrica. 
Figura 5 - Ubá (MG): Mapa de classificação morfométrica, 2019.
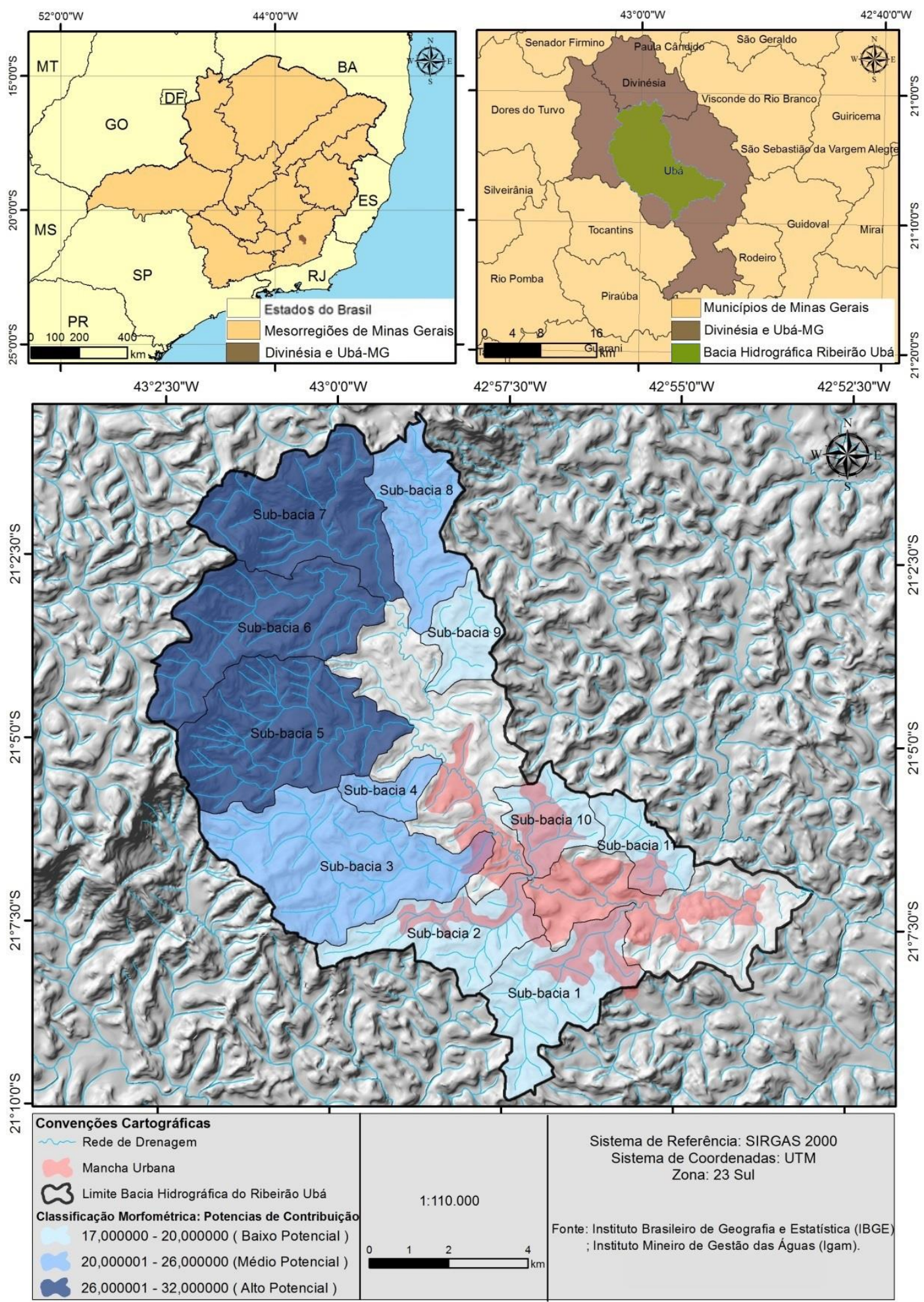

Fonte - Elaborado pelos autores.

As sub-bacias hidrográficas com alto potencial de contribuição apresentaram particularidades, estas exemplificadas por valores elevados, concebidos através dos seguintes parâmetros: área, percentual de canais de primeira ordem, amplitude altimétrica, declividade média do canal e da bacia. Estes fatores, conferiram a esse grupo de sub-bacias diferentes dinâmicas no que tange as suas características hidrológicas e geomorfológicas, imprimindo a elas caráter de forte

Caminhos de Geografia $\quad$ Uberlândia-MG $\quad$ v. 22, n. $82 \quad$ ago./2021 $\quad$ p. 201-214 Página 211 
influência sobre os fenômenos de inundações deflagrados à jusante da bacia hidrográfica do Ribeirão Ubá, mais precisamente na malha urbana da cidade.

As áreas de drenagem encontradas variaram de $12,56 \mathrm{~km}^{2}$ a $15,42 \mathrm{~km}^{2}$, aspecto este que confere a esse grupo de sub-bacias características de pequeno porte, entretanto, levando-se em consideração a área total da bacia hidrográfica do Ribeirão Ubá, temos que este grupo ocupa quase que metade da área de estudo, totalizando um percentual de $42,6 \%$.

Os valores referentes ao índice de sinuosidade mostraram-se elevados levando-se em consideração o contexto presente na área de estudo, temos que quanto maior for o valor do referido índice, menor a velocidade do escoamento. Os comprimentos dos canais principais variaram de 7,04 km a 9,88 km, com índices de sinuosidade variando de 1,24 a 2,11, imprimindo a esse grupo de sub-bacias hidrográficas um padrão de drenagem naturalmente meândrico, entretanto, tal característica, evidenciada pela presença de controle estrutural, encontra-se associada a maior presença percentual de canais de primeira ordeme de declives acentuados.

O maior percentual de canais de primeira ordem encontrado, associado a essa conjuntura de relevos, contribuirá de forma direta para a conversão do fluxo de vertente em fluxo fluvial em um espaço curto de tempo. Essas características associadas à presença de declives acentuados e pela considerável amplitude altimétrica, conferem a essas sub-bacias hidrográficas elevada energia do relevo, constituindo um cenário propicio em partes para o aumento da capacidade da velocidade de escoamento superficial nesses locais e consequentemente para o menor tempo de concentração das águas, que tende, portanto, a escoar e a se acumular à jusante.

\section{CONCLUSÃO}

O estudo das características morfométricas de bacias hidrográficas mostrou-se como uma importante ferramenta para compreensão do contexto no qual estão inseridas, ampliando e contribuindo para medidas primárias de auxilio e inserção de um referencial técnico e teórico no que se refere a futuras elaborações de planos de manejo voltados a gestão de bacias hidrográficas e de seus recursos hídricos. Nesse contexto, o uso do Sistema de Informação Geográfica (SIG), apresentou-se como meio importante no georreferenciamento, gestão, análise espacial, edição e manipulação dos dados necessários à elaboração da análise morfométrica, facilitando e agilizando a interpretação de um grande número de dados utilizados na comparação entre as sub-bacias hidrográficas e dos seus respectivos potenciais de contribuições ao desenvolvimento de inundações na malha urbana de UbáMG.

Faz-se importante ressaltar que os resultados referentes às análises morfométricas podem suscitar interpretações que vão além do que foi aqui descrito. Ou seja, levando-se em conta os resultados obtidos, pode-se inferir que tais procedimentos subsidiam de forma parcial a investigação das causas do fenômeno de inundações, uma vez que os dados extraídos através das técnicas de geoprocessamento possuem valor subjetivo senão correlacionados à trabalhos de campo, visto que a complexidade do real pode acarretar em alterações dos conteúdos trabalhados somente em gabinete. Nesse cenário se faz evidente a necessidade de se aplicar novas pesquisas na região e mapeamentos em escalas que possibilitem maior detalhamento das informações a serem analisadas, buscando assim reduzir os erros nas interpretações dos condicionantes que interferem de forma direta no desenvolvimento de inundações.

\section{REFERÊNCIAS}

AB'SÁBER, A. N. Os domínios de natureza no Brasil. Potencialidades paisagísticas. 6. ed. São Paulo: Ateliê Editorial, 2003. $55 \mathrm{p}$ 
ANDRADE, M. C de. Aspectos Geográficos da Região de Ubá. Anais da Associação dos Geógrafos Brasileiros, São Paulo, Avulso, n. 1, 1961.

ANTONELI, V; THOMAZ, E.L. Caracterização do meio físico da bacia do Arroio Boa Vista, GuamirangaPR. Rev. Caminhos da Geografia, Uberlândia, v.8, n.21, p46-58, jun. 2007.

CHARLTON, R. Fundamentals of fluvial geomorphology. New York: Routledge, 2008. 280 p. https://doi.org/10.4324/9780203371084

CHEREM, L. F. S. Análise Morfométrica da Bacia do Alto Rio das Velhas - MG. 2008. 96 f. Dissertação (Mestrado) - Curso de Geografia, Instituto de Geociências, Universidade Federal de Minas Gerais, Belo Horizonte, 2008. Cap.1.Disponívelem:<http://www.csr.ufmg.br/modelagem/dissertacoes/luizfelipecherem.pdf>. Acesso em: 01 dez. 2014.

CHRISTOFOLETTI, A. Geomorfolgia. São Paulo: Edgar Blucher, 1980.

CHRISTOFOLETTI, A. Geomorfolgia fluvial. São Paulo: E. Blucher, 1981.

ESRI - Environmental Systems Research Institute. ArcGIS Software. Disponível em < http://www.esri.com/software/arcgis/index.html>. Acesso em: 20 dez. 2020.

IBGE - Instituto Brasileiro de Geografia e Estatística. Cidades,2010. Disponível em: http://www.ibge.gov.br. Acesso em 01 dez. 2020

IBGE - Instituto Brasileiro de Geografia e Estatística. Cidades,2020. Disponível em: http://www.ibge.gov.br. Acesso em 01 dez. 2020.

IGAM - Instituto Mineiro de Gestão das Águas. Mapoteca,2010. Disponível em: <http://www.igam.mg.gov.br/>. Acesso em: 04 dez. 2019.

IPT - Instituto de Pesquisas Tecnológicas. Mapeamento de riscos em encostas e margens de rios. Brasília: Ministério das Cidades; Instituto de Pesquisas Tecnológicas - IPT, 2007. 176 p. Disponível em: Acesso em: 26 ago. 2020.

JENKS, G. The data model concept in statistical mapping. International Cartographic Association ed. International Yearbook of Cartography 7, p. 186 - 190, 1967.

LIMA, K. C et al. Análise geomorfométrica da bacia hidrográfica do rio bom sucesso (semiárido da Bahia) através da aplicação de parâmetros morfométricos da rede de drenagem. Revista de Geografia, Recife, Ufpe, v., n. 2, p.30-44, 2010

MACHADO, P. J. O. Bacia Hidrográfica. In: MACHADO, P. J. O. Introdução à Hidrogeografia. São Paulo: Cengage Learning, 2012. Cap. 4. p. 37-67.

MICROSOFT OFFICE. Excel. Disponível em < https://www.microsoft.com/pt-br/microsoft-365/excel>. Acesso em: 20 dez. 2020.

MIRANDA, F.M. Índice de Susceptibilidade do Meio Físico a Inundações como Ferramenta para o Planejamento Urbano. Rio de Janeiro: UFRJ/COPPE, 2016.

SOUZA, C. R. de G. Suscetibilidade morfométrica de bacias de drenagem ao desenvolvimento de inundações em áreas costeiras. Revista Brasileira de Geomorfologia, [s. L.], v. 1, n. 6, p.45-61, 2005. https://doi.org/10.20502/rbg.v6i1.38

SOUZA, C. C. de. Avaliação dos Impactos Ambientais da Atividade Industrial no Polo Moveleiro de Ubá - MG. 2008. 165f. Dissertação (Mestrado em Ciência Florestal) - Universidade Federal de Viçosa, Viçosa, MG, 2008. Disponível em: https://locus.ufv.br//handle/123456789/2969 . Acesso em: 20 set. 2015. 
SUMMERFIELD, M.A. Global Geomorphology, John Wiley \& Sons, 1991, 537p.

TUCCI, C. E. M. Controle de Enchentes. In: TUCCI, Carlos E. M. (Org.). Hidrologia: Ciência e aplicação. 2. ed. Porto Alegre: Editora da Universidade/UFRGS, 2000. Cap. 16. p. 621-652.

TUCCI, C. E. M.; BERTONI, Juan Carlos (Org.). Inundações Urbanas na América do Sul. Porto Alegre: Editora ABRH, 2003. $129 \mathrm{p}$.

VALVERDE, O. Estudo Regional da Zona da Mata de Minas Gerais. Revista Brasileira de Geografia, Rio de Janeiro, v. 20, n. 1, p.3-82, jan. 1958.

UBÁ (Município). Plano de Gestão dos Serviços de Abastecimento de Água Potável e Esgotamento Sanitário, 2011. Disponível em: http://www.uba.mg.gov.br/abrir_arquivo. aspx/Consulta_Publica?cdLocal=2\&arquivo $=\{84133 B 8 B-E C D D-E 664-5 E D 8-$

2EAE1E7E1EA'2\}.pdf\#search=retificação do ribeirão ubá. Acesso em: 13 jul. 2014.

Recebido em: 06/07/2020

Aceito para publicação em: 23/12/2020 